\title{
ELEMENTARY SCHOOL TEACHERS' COMPREHENSION OF DATA DISPLAYS
}

\author{
TIMOTHY JACOBBE \\ University of Florida \\ jacobbe@coe.ufl.edu \\ ROBERT M. HORTON \\ Clemson University \\ bhorton@clemson.edu
}

\begin{abstract}
This study investigated elementary school teachers' comprehension of data displays. Assessment, interview, and observation data were analyzed to determine their level of comprehension. Results revealed that the teachers were proficient at "reading the data" and computation types of "reading between the data" questions, but were unsuccessful with questions that assessed higher levels of graphical comprehension. Many of the difficulties exhibited by the teachers appear to be attributable to a lack of exposure to the content. Implications for teacher preparation, professional development, and curricula development are discussed.
\end{abstract}

Keywords: Statistics education research; Content knowledge; Graphical displays; Teacher preparation

\section{INTRODUCTION}

Over time, several efforts have been undertaken in the United States to increase the quantity and depth of coverage of statistical topics throughout the K-12 curriculum. The efforts in the United States to include more statistics and data analysis in the K-12 curriculum parallel efforts in other countries such as Australia, New Zealand, Ireland, and Israel. A first step in ensuring K-12 teachers are prepared to teach statistics is to explore the current status of their knowledge. Although this study is situated in the United States, the results translate to other countries as the implementation of statistics in the school curriculum at a sophisticated level is a newfound endeavor. This is particularly true at the elementary school level, which is the focus of this paper.

\subsection{BACKGROUND ON THE INCLUSION OF STATISTICAL TOPICS IN THE UNITED STATES CURRICULUM}

In the United States, the efforts of the Quantitative Literacy Project (Scheaffer, 1986) influenced the development of the national mathematics standards (National Council of Teachers of Mathematics, 1989, 2000). In these Standards, NCTM has increased the depth of statistical ideas that should be taught in elementary, middle, and secondary schools. This increase has continued with the release of the Guidelines for Assessment and Instruction of Statistics Education (GAISE) (Franklin et al., 2007). Whether teachers have the requisite knowledge to teach this content effectively is an important

Statistics Education Research Journal, 9(1), 27-45, http://www.stat.auckland.ac.nz/serj

C International Association for Statistical Education (IASE/ISI), May, 2010 
consideration. This paper looks at elementary teachers' comprehension of data displays in regard to several key ideas identified by NCTM (2000) for all students in grades 3-5 (ages 9-11):

- Recognize the differences in representing categorical and numerical data.

- Describe the shape and important features of a set of data and compare related data sets, with an emphasis on how the data are distributed.

- Compare different representations of the same data and evaluate how well each representation shows important aspects of the data.

The Standards identified above are further delineated in the GAISE framework. The GAISE framework identifies three levels of statistical development (Levels A, B, and C) that students must progress through in order to develop statistical understanding. Grade ranges for these levels are intentionally unspecified; however ideally Levels $\mathrm{A}, \mathrm{B}$, and $\mathrm{C}$ would correspond with elementary (Grades K-5/Ages 5-11), middle (Grades 6-8/Ages 1214), and high school (Grades 9-12/Ages 15-18), respectively. "Without such experiences, a middle [or high] school student who has had no prior experience with statistics will need to begin with Level A concepts and activities before moving to Level B” (Franklin et al., 2007, p. 13). The following discussion outlines what the GAISE call for at Levels A and B in regard to data displays. Keep in mind that these refer to the development of students' knowledge; teachers' knowledge must necessarily exceed the level that they are called upon to teach. These recommendations are consistent with and expand upon the recommendations of Friel, Curcio, and Bright (2001) in their meta-analysis of research related to making sense of graphs.

Level A Throughout their experiences at Level A, students should be exposed to a variety of displays for exploring distributions and association. These displays should include frequency tables, bar graphs, stem-and-leaf plots, dotplots, scatterplots, and time plots (Franklin et al., 2007, p. 32). The GAISE specifically indicate that students at Level A should not be exposed to pictographs or circle graphs as these "type[s] of graph[s] require a basic understanding of proportional or multiplicative reasoning" (p. 25). Students, however, should be exposed to the nature of variables, as they should understand that bar graphs are used to summarize categorical data, where histograms, which are introduced at Level B, represent numerical data. "At Level A, appropriate graphical displays for numerical data are the dotplot and stem-and-leaf plot” (p. 35).

Level B The concepts discussed at Level B are a continuation of the experiences students are exposed to at Level A. Students should master ideas relating to histograms, frequency tables, grouped frequency and relative frequency tables, boxplots and timeseries plots. Students at Level B should also investigate misuses of data displays in the media, in particular pictographs that compare distributions inappropriately.

\subsection{RESEARCH RELATED TO TEACHERS' COMPREHENSION OF DATA DISPLAYS}

There has been very little research conducted on teachers' comprehension of data displays. One study considered high school students in an Advanced Placement statistics course and college students in an introductory statistics course (delMas, Garfield, \& Ooms, 2005), whereas another study used some of the same assessment items to investigate preservice teachers in Spain (Espinel, Bruno, \& Plasencia, 2008). The 
theoretical work related to describing various levels of comprehension of graphs (e.g., Curcio, 1987; Friel et al., 2001) will be discussed later in this paper.

The work of delMas et al. (2005) involved using multiple-choice assessment items that were developed through the NSF-funded Assessment Resource Tools for Improving Statistical Thinking (ARTIST) project. These assessments items involved both statistical literacy and reasoning. Across all of the assessment items, the students enrolled in the Advanced Placement classes outperformed students in an introductory statistics course at the collegiate level; however delMas, Garfield, and Ooms found areas of difficulty for both groups of students. They summarize these difficulties by stating

Students revealed difficulty in many aspects of reasoning about graphical representations of distributions. In particular, they had difficulty reading the data when the bars contained intervals of values rather than single values of a variable. They probably were not sure of what the axes actually represented. And most of all, they seemed to prefer graphs where a bar represents a single value or case, rather than a frequency. (p. 5)

Espinel et al. (2008) utilized four of the same items from the ARTIST project to assess preservice teachers in Spain. Unfortunately, the level of schooling these preservice teachers were being trained to teach was not reported. In this study, Espinel et al. compared the performance of the preservice teachers to that of the college students enrolled in an introductory statistics course in the delMas et al. (2005) study described above. On all four questions, the preservice teachers performed lower than the college students in the United States. In particular, preservice teachers had difficulty distinguishing between continuous and discrete variables. Espinel et al. concluded that

the results suggest that future teachers struggled when reasoning about graphs... . The training received by the teachers was only useful in helping them understand the explicit information in the graphs but did not help them reason beyond the information provided. (p. 5)

Research involving teachers' comprehension of statistical topics is just beginning to surface and research thus far has primarily been focused on teachers' understanding of measures of center (e.g., Batanero, Godino, \& Navas, 1997; Cai \& Gorowara, 2002; Callingham, 1997; Gfeller, Niess, \& Lederman, 1999; Groth \& Bergner, 2006; Jacobbe, 2008; Leavy \& O’Loughlin, 2006; Russell \& Mokros, 1990). Although a review of the literature does not reveal any prior studies directly related to elementary school teachers' comprehension of data displays, there are two other studies involving elementary school teachers related to the topic. Begg and Edwards (1999) focused on the teaching of statistics at the elementary school level and Greer and Ritson (1994) explored the selfreported readiness of teachers to teach statistics in Ireland.

The data from the Begg and Edwards study were based on "unstructured, semistructured, and clinical interviews; [and] survey (Likert) scales that provided a guide with respect to the efficacy of the research” (1999, p. 2). The sample included 22 inservice elementary school teachers and 12 preservice elementary school teachers in New Zealand. The majority of teachers was female (specific number not reported) and many of the inservice teachers had substantial teaching experience (mean number of years not reported).

In general, teachers' attitudes toward statistics were negative. Some of the words they associated with the subject were "fear, horrors, uninteresting, boring, and horrible graphs” (Begg \& Edwards, 1999, p. 2). Begg and Edwards found that teachers did not rate the importance of teaching statistics at the elementary level very high. Nor did teachers consider the development of a deeper understanding of statistics important. When teachers were asked whether they would prefer professional development which 
focused on statistical understanding of the topics they taught or on activities for students, the teachers most often preferred obtaining activities. This preference was despite their own self-admitted lack of understanding of statistics. This lack of understanding was further evident in that most of the teachers were "unfamiliar with one or more of the [statistical] terms taken from the curriculum" (p. 8).

In order to explore the readiness of elementary teachers in Northern Ireland to teach statistics, Greer and Ritson (1994) interviewed 16 elementary and 24 high school teachers. The interviews contained open-ended questions and prompts to raise issues of importance to the teachers. The authors concluded that, although there is reason for concern at both levels, "judging by this sample, [elementary school] teachers are illprepared to teach [statistics]" (p. 52). This was based on the teachers' responses which indicated that, of the 16 elementary school teachers, $94 \%$ felt they were not taught the content during their teacher training courses, $63 \%$ felt they had never learned about the topics since then, and $88 \%$ felt they did not understand the mathematics necessary to teach the topics.

Though these studies did not directly assess the elementary school teachers' comprehension of data displays, they suggest that teachers may not have "taken possession of the content themselves” (Begg \& Edwards, 1999, p. 10).

\subsection{STATISTICAL KNOWLEDGE FOR TEACHING}

In their seminal article, Hill, Ball, and Schilling (2008) indicate the importance of distinguishing between subject matter knowledge and pedagogical content knowledge. They express that teachers, unlike the general population, need to possess knowledge of content and students. The focus of this paper is on subject matter knowledge. There are two main components to subject matter knowledge - common content knowledge (CCK) and specialized content knowledge (SCK). Common knowledge is knowledge that can be gained from standard content courses and it is what can be expected of anyone that utilizes that content in their profession. Specialized knowledge is related to the development of knowledge of issues or misconceptions that may come up during the course of instruction.

Groth (2007) used the work concerning mathematical knowledge for teaching to hypothesize aspects of statistical knowledge for teaching. As Groth pointed out, there are vast differences between mathematics and statistics. (See also delMas, 2004.) Groth went on to utilize the four components of statistical problem solving presented in the GAISE framework as a means to articulate the statistical knowledge for teaching. This model is very powerful and should inform future studies in relation to teachers' statistical knowledge.

Similar to the Groth and Bergner (2006) study, the results presented in this paper mainly consider teachers' common knowledge; however there are some tasks (e.g., Figure 4 below) and observation data that can also considered specialized content knowledge. Based upon the review of literature concerning teachers' understanding of data displays it is difficult to develop specialized content knowledge without the foundation of common content knowledge. As articulated in the implications for this study, both should be addressed either during teacher preparation or professional development programs.

\subsection{THEORETICAL FRAMEWORK AND RESEARCH QUESTION}

This paper and the associated research are based on a schema-theoretic framework. The levels of development described in the GAISE framework are aligned with this 
framework and stem from the work of Curcio (1987). Curcio adapted a framework intended to describe general discourse concerning the mathematical relationships expressed in data displays. This framework is based on the premise that knowledge "depends upon the amount of previous meaningful exposure to the topic" (p. 383) a particular person has had. In relation to data displays, in order to acquire knowledge, individuals need to have had meaningful prior experience with the topic, the associated mathematical content, and the form or type of graph.

The research presented in this paper provides a snapshot of elementary school teachers' comprehension of data displays with respect to the expectations outlined in Levels A and B of the GAISE framework. Although we cannot determine exactly what is in the teachers' minds and what they do or do not know about data displays, we collected evidence regarding their overarching comprehension of data displays as evidenced by their performance on specific tasks. If teachers have not had meaningful experiences with data displays, which go beyond simply reading the data (discussion forthcoming), then it is unreasonable to expect them to teach students to consider data displays in a more sophisticated manner. This is consistent with a positivist epistemology of practice where teachers that do not have the internal facility or preparation to deal with more sophisticated uses of data displays will not be able to interpret the data in a more complex manner (Schön, 1983). It is important to note that if it is the case that teachers have not had sufficient experiences, then it is clearly not the fault of the teachers for not having that knowledge. The difficulty lies in increasing expectations for students without first addressing teachers' preparation to meet those expectations.

The research question was as follows:

What is the understanding of elementary school teachers in the area of data displays with respect to the expectations set forth in the GAISE framework?

\section{METHOD}

Three teachers identified as strong mathematics teachers were selected in order to provide insight as to what some of the best teachers comprehend. Using qualitative techniques from an interpretive approach (Miles \& Huberman, 1994), the primary researcher spent extensive time in the field conducting observations, interviews, and administering assessments to these three participants. This method was utilized to provide researchers with a practical understanding of what may be expected of elementary school teachers that are identified as exemplary.

\subsection{SETTING AND PARTICIPANTS}

This study was conducted in a middle- to upper-middle class school district located in the Mid-Atlantic Region of the United States. A district supervisor for mathematics and science education recommended a group of teachers to participate in the study based on their qualifications and high standing. Several teachers were observed, interviewed, and surveyed before deciding on the three teachers used as the focus of this study. The three participants were selected because they were rated highly, were willing to dedicate the necessary time involved with the study, and were open regarding their understanding of statistics. In particular, these teachers were selected because they were effective in developing interest in mathematics and in motivating students to succeed, and they did an excellent job, as evidenced by standardized test scores, in developing number sense and skills. 
One of the participants (Ms. Alvin) taught Grade 4, and the other two (Ms. Brown and Ms. Clark, all pseudonyms) taught Grade 3. Ms. Alvin was the most senior of the three with 9 years experience (all at the Grade 4 level). Ms. Brown and Ms. Clark had 5 and 4 years experience (all at the Grade 3 level), respectively.

\subsection{MEDIUM FOR THE STUDY}

A curriculum series, Math Out of the Box@ (see Moss, Diaz, Lashley, Moss, \& Sanders, 2005), served as the medium to investigate these teachers' comprehension of data displays, and associated ideas of types of variables and measures of center. One of the primary reasons for working with these materials was that the activities address many of the objectives identified at Levels A and B in the GAISE framework, including the use and interpretation of data displays. This content is uncommon in many traditional elementary school textbooks. Furthermore, as part of the pilot program for the series, the lessons on data displays were required to be administered. Again, it is not uncommon to find schools that skip sections on statistics. This setting and this medium provided a meaningful context to explore the teachers' comprehension of data displays.

\subsection{THREE PHASES OF DATA COLLECTION}

This study presents results from a larger case study involving these elementary school teachers' understanding of several statistical content areas (see Jacobbe, 2007). As a result, not all of the data collected over the course of the study were directly related to teachers' comprehension of data displays. For example, some of the lessons observed and interviews did not involve the presentation and interpretation of data displays. The data presented here stem from three phases of data collection; however the majority of information presented was collected on assessments during Phase Three of data collection.

In Phase One, baseline data were collected on the teachers. This phase involved meeting with the teachers and conducting a baseline interview before the first, or in the case of Ms. Alvin second, implementation of the Math Out of the Box materials.

In Phase Two, data were collected on the teachers as they implemented the Math Out of the Box materials. This phase began with an eight-hour professional development training on statistics provided by the creators of the Math Out of the Box materials. As the teachers began implementation of the materials, the researcher served as a passive observer during five classroom visits (each lasting approximately 50 minutes) per teacher. Transcripts of the lessons were used to analyze the statistical content covered in each class as well as to determine whether any misconceptions were exhibited by the teachers during instruction. There was also a formal, 30-minute interview focused on statistical content conducted after the implementation of the materials.

In Phase Three, data were collected as the teachers implemented the materials for the second (Ms. Brown and Ms. Clark) or third (Ms. Alvin) time. As in Phase Two, observations and interviews were conducted. In addition, an in-depth assessment of the teachers' content knowledge was conducted. This level of analysis involved topics related to the concepts introduced at the teachers' particular grade level and to the teachers' understanding of topics suggested for Level B of the GAISE. Questions were taken from established assessments, specifically the National Assessment of Educational Progress (NAEP) and the Diagnostic Mathematics Assessments for Elementary Teachers (DTAMS) developed by the Center for Research in Mathematics and Science Teacher 
Development at the University of Louisville (Saderholm, Ronau, Todd Brown, \& Collins, 2010).

\subsection{LIMITATIONS}

This study was primarily limited by the sample size. By examining only three purposefully selected teachers, generalizations to all elementary school teachers are not appropriate. This was a collective case study using a mixed methods design. The researchers believed that studying three highly recommended and successful teachers in depth should paint a fairly vivid portrait of what we might expect from the "best" teachers.

This study was also limited by the perspective with which teachers' comprehension was measured. As with any study concerning comprehension, one cannot determine exactly what is going on in participants' minds. What is presented is the performance exhibited by teachers on specific tasks. It is possible that the participants involved in this study possessed a different level of comprehension than what the results show; however the results are presented based solely on the data that were collected. Additionally, it would have been advantageous to use the same assessment instruments developed through the ARTIST project and reported on by delMas et al. (2005).

\subsection{FRAMEWORK FOR TASK CATEGORIZATION}

In their seminal article focused on making sense of graphs, Friel et al. (2001) described graph comprehension as "readers' abilities to derive meaning from graphs created by others or by themselves. Different levels of questioning provoke different levels of comprehension" (p. 132). In their analysis of the ways authors have characterized tasks related to graphs, they found that several authors (Bertin, 1983; Carswell, 1992; Curcio, 1987; McKnight, 1990; Wainer, 1992) had a similar method of distinguishing among tasks in three ways. Curcio (1987) was first to use the trichotomy of "reading the data," "reading between the data," and "reading beyond the data." Reading the data simply involves taking information from a graph. Reading between the data involves taking information from a graph and doing some type of reasoning with that information. Finally, reading beyond the data involves extending the information given in the data display to a new situation or to make a prediction.

It has been argued (Shaughnessy, 2007; Shaughnessy, Garfield, \& Greer, 1996) that an additional category - reading behind the data - should be included in relation to graph comprehension. Reading behind the data involves making a connection between the context and the graph itself. In other words, it goes further than reading beyond the graph in that it deals with investigating influences that may have affected various trends that are observed. This particular category was not addressed in assessing teachers' common knowledge and may be viewed as an additional limitation to the study.

Friel et al. (2001) suggested the following taxonomy of tasks:

One Quantity: Readers identify a value in a graph and do not do anything with that value.

Two+ Quantities: Readers use two or more data values to answer the questions. This second category was further broken down to distinguish among tasks that involve (a) performing computations, (b) making comparisons, and (c) identifying trends.

In this study, the taxonomy suggested by Friel et al. (2001) are used with slight modifications. We attempt to expand upon their work to introduce a more inclusive 
categorization scheme for coding purposes. Each of the tasks involved in this study is categorized in one of the following five areas:
I. Reading the Data
II. Computations
III. Comparisons
IV. Trends
V. Selection and Construction of Data displays.

Category I is associated with Curcio's reading the data, Categories II and III with reading between the data, and Category IV with reading beyond the data. Category V deals with the underlying understanding of data displays from selecting and constructing a graph to realizing which type of variable (i.e., categorical or quantitative) is associated with which type of data display. This additional category is included because "very little is known about the relationship between the development of graph comprehension and the practice of creating graphs within the context of statistical investigations" (Friel et al., pp. 132133). Future studies should include an additional category to investigate Shaughnessy's notion of reading behind the data.

The characterization of each question is shown in Table 1 . There were few Comparison (Category III) and Trend questions (Category IV) as these types of questions are more common at Levels $\mathrm{B}$ and $\mathrm{C}$ as described in the GAISE framework. The categorizations were verified by two independent reviewers who were mathematics assessment specialists. For questions where reviewers did not initially agree, a meeting was held to reach agreement on the categorization of the question.

Table 1. Summary of Questions

\begin{tabular}{ll}
\hline Categories & Total \\
\hline I (Reading the Data) & 17 \\
II (Computations) & 8 \\
III (Comparisons) & 4 \\
IV (Trend) & 2 \\
V (Selection and Construction of Data Displays) & 11 \\
\hline Total & 42 \\
\hline
\end{tabular}

\section{DISCUSSION AND RESULTS}

\subsection{OVERALL PERFORMANCE}

Table 2 shows the teachers' performance in each category. The teachers answered 82\% of the Reading the Data (Category I), 79\% of the Computations (Category II), 92\% of the Comparison (Category III), $0 \%$ of the Trend (Category IV), and $52 \%$ of the Selection and Construction of Data Displays (Category V) questions. The teachers did better in Reading the Data (Category I), performing Computations (Category II), and Comparisons (Category III) (collectively 83\%) than in Trends (Category IV) and Selection and Construction of Data displays (Category V) (collectively 44\%).

Given the nature of this study, all of the data collected during assessments, observations, and interviews were not necessarily related to the teachers' comprehension of data displays. Miles and Huberman (1994) describe a checklist matrix as a useful tool in summarizing data to present results. As part of the analysis process, information was used from multiple sources to determine what type of comprehension was exhibited in the five categories. The checklist matrix shown in Table 3 is an attempt to summarize the evidence of understanding or lack of understanding that was evident through the analysis 
Table 2. Teachers' Performance

\begin{tabular}{llll}
\hline Teacher & Category & Correct & Incorrect \\
\hline Ms. Alvin & I & 14 & 3 \\
& II & 5 & 3 \\
& III & 4 & 0 \\
& IV & 0 & 2 \\
& V & 5 & 6 \\
\hline Ms. Brown & I & 13 & 4 \\
& II & 6 & 2 \\
& III & 3 & 1 \\
& IV & 0 & 2 \\
& V & 5 & 6 \\
\hline Ms. Clark & I & 15 & 2 \\
& II & 8 & 0 \\
& III & 4 & 0 \\
& IV & 0 & 2 \\
& V & 7 & 4 \\
\hline
\end{tabular}

process. Because all three teachers responded in a very similar manner in regard to tasks focused on comprehension of data displays, see Table 2 above, the checklist matrix will be used in an attempt to summarize the overall comprehension of all three teachers.

Table 3. Checklist Matrix on Comprehension of Data Displays

\begin{tabular}{lll}
\hline Ms. Alvin, Ms. Brown, and Ms. Clark & \\
\hline Cat & Evidence of Comprehension & Evidence of Lack of Comprehension \\
\hline I & $\begin{array}{l}\text { All three teachers were able to identify } \\
\text { information presented in data displays in } \\
\text { order to answer identification type } \\
\text { questions. }\end{array}$ & $\begin{array}{l}\text { The areas where the three teachers struggled } \\
\text { involved data displays with which the } \\
\text { teachers were not familiar (e.g., boxplot and } \\
\text { stem-and-leaf). (See Figures 1 and } 2 \text { below.) }\end{array}$ \\
\hline II & $\begin{array}{l}\text { The teachers were generally successful on } \\
\text { all questions that required them to } \\
\text { identify information and perform some } \\
\text { type of computation. These generally } \\
\text { involved finding one or more measures of } \\
\text { center. }\end{array}$ & $\begin{array}{l}\text { The only teacher that exhibited an issue with } \\
\text { these questions was Ms. Alvin who had a } \\
\text { tendency to calculate the incorrect measure of } \\
\text { center. This was an issue with her lack of } \\
\text { comprehension of measures of center rather } \\
\text { than her lack of graphical comprehension. }\end{array}$ \\
\hline $\begin{array}{l}\text { The teachers were successful in } \\
\text { answering most questions where they had } \\
\text { to make a comparison. This generally } \\
\text { involved comparing how many more a } \\
\text { particular category had than another. }\end{array}$ & $\begin{array}{l}\text { The teachers did not reveal difficulty in this } \\
\text { area. The one error that occurred was } \\
\text { attributed to a careless error. }\end{array}$ \\
$\begin{array}{l}\text { The teachers did not reveal much } \\
\text { understanding in this area; however there } \\
\text { were very few questions in this category. }\end{array}$ & $\begin{array}{l}\text { Teachers had issues with realizing that the } \\
\text { data said something more than what they } \\
\text { could see in the display. }\end{array}$ \\
\hline $\begin{array}{l}\text { The teachers understood how to identify } \\
\text { appropriate graphs as in Figure 3. They } \\
\text { were also able to instruct students how to } \\
\text { appropriately construct a line plot. (See } \\
\text { transcript comments 1 - 24 below.) }\end{array}$ & $\begin{array}{l}\text { The teachers struggled with issues associated } \\
\text { with appropriate data displays for situations } \\
\text { where they had to distinguish between } \\
\text { categorical and numerical data. (See } \\
\text { transcript comments 25 - 38 below.) }\end{array}$ \\
\hline
\end{tabular}

The focus of the remaining sections of this paper is on the teachers' performance in Categories I and V. The teachers performed relatively well in Category II and discussion regarding their performance in this area generally involves issues in relation to their 
understanding of measures of center rather than graphical comprehension. Categories III and IV were included in this study only in a minor manner. Further analysis of the results presented above comes from examining specific questions as well as analysis of qualitative data collected through observations in the classroom.

\subsection{DISCUSSION OF SPECIFIC EXAMPLES FROM THE DATA COLLECTION PROCESS}

As presented in Table 3, the difficulty teachers experienced in Category 1 stemmed from a lack of experience with particular data displays. All three teachers were unsuccessful in their attempts to answer the questions involving stemplots and boxplots. The questions involving a stem-and-leaf plot and boxplot are shown in Figures 1 and 2. These questions come from the DTAMS.

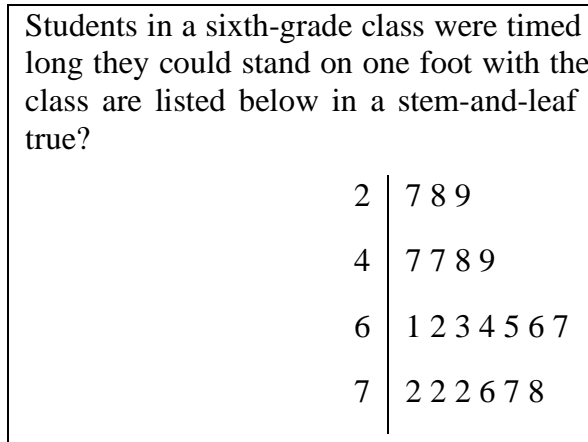

a. The shortest time was 28 seconds

b. Half the class had times under 58 seconds

c. The longest time was 77 seconds

d. $50 \%$ of the class had times over 63 seconds

Figure 1. Stem-and-Leaf Plot Question

The box-and-whiskers plot below represents the test scores of three classes on the same test.

a. Which class performed the best and which class performed the worst?

b. Provide justifications for your choices with data from the box-andwhiskers plots.

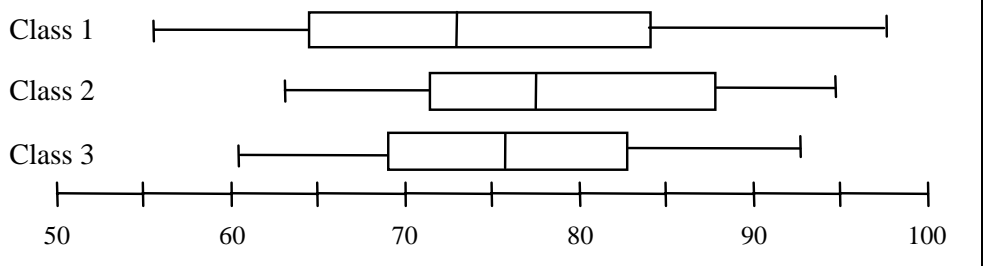

Figure 2. Boxplot Question

After taking this assessment, all three teachers commented that they had never seen such a graphical display and had "no clue" how to answer such a question. Although the question in Figure 2 involves far more than reading the data, the teachers did not have a 
means of considering the information presented as they did not have experience with this type of display. This lack of comprehension is likely rectified by exposing teachers to various data displays during teacher preparation or professional development programs.

By examining the difference in performance by the three teachers in regard to the two questions involving circle graphs, one may begin to distinguish between the types of questions that were used to assess teachers' ability to select and construct various types of data displays (Category V). These questions also begin to distinguish between common content knowledge and specialized content knowledge. Both of these questions were selected from the DTAMS. Figure 3 shows a question that involved the teachers selecting the most appropriate graphical display when the data were represented as percentages of a whole.

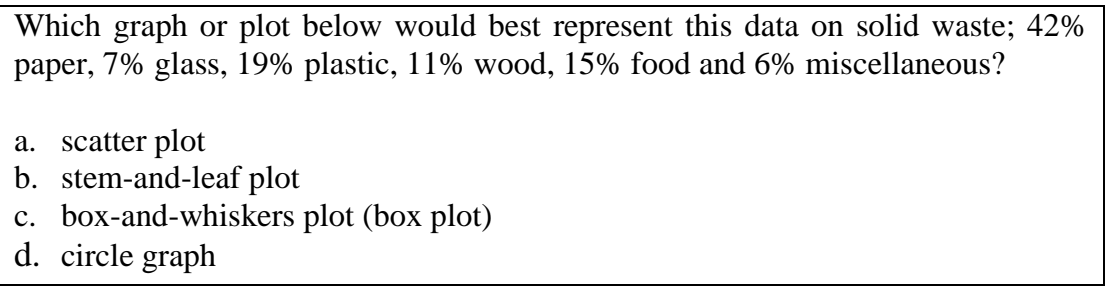

Figure 3. Selecting an Appropriate Graph

Figure 4 shows a question that required the teachers to consider how the central angles of a circle graph should be constructed to represent the data appropriately.

A survey of middle school students resulted in data about the quantity of soft drinks they consumed in a week. The data is displayed in the table below:

\begin{tabular}{|l|l|l|l|l|l|}
\hline \# of drinks & 2 or fewer & 3 & 5 & 6 & over 7 \\
\hline \# of students & 4 & 6 & 7 & 5 & 3 \\
\hline
\end{tabular}

The students were asked to construct a circle graph for the data. One student determined the size of the angles for each section of the graph by determining the size of each angle, such that $\left(4 / 25=16 / 100=16^{\circ}\right)$. The student drew the angles with a protractor and had space left over. (a) What error is this student making, and (b) how would you help her?

Figure 4. Constructing a Circle Graph

Both questions in Figures 3 and 4 were from Category V and are at Level B of the GAISE framework. All three teachers were successful at answering the question in Figure 3 ; however all were unsuccessful at answering the question in Figure 4.

Similar to the findings of Begg and Edwards (1999), the issues teachers' experienced with Figures 1, 2, and 4 above can mainly be attributed to a lack of experience in relation to statistics. An example of that can be seen with how the teachers introduced the process of constructing a lineplot to students. Keep in mind that this process was the major focus of the only professional development experience the teachers received in connection with teaching statistics through the Math Out of the Box curriculum. Prior to this professional development experience, all three teachers were unfamiliar with the lineplot as a data display. All three teachers introduced this process to their students in a similar manner to what is represented in transcript comments 1 to 24 . In this lesson the teacher was working with students to change the data display representing students' wrist sizes from a tally table to a lineplot. 
1. Ms. Brown: I think we should organize the information in another way. I saved your post-it notes and I'm going to give them back to you.

2. Student: It's a line plot

3. Ms. Brown: How do you know?

4. Student: I remember from doing Homeruns (a previous example that was used and displayed in a lineplot).

5. Ms. Brown: What would we use this for?

6. Student: So we can get information from it by putting things in groups.

7. Ms. Brown: Anyone else?

8. Student: To put it on a graph

9. Ms. Brown: Anyone else?

10. Student: To organize data or to arrange it.

11. Ms. Brown: Let's try it. You got your post-it notes. How can we use them?

12. Student: We can put them on the graph where our wrist sizes should go.

Ms. Brown called upon students, one at a time, to put their post-it notes on the line plot that represented their wrist size. In the end the line plot had 2 post-it notes above 5 , 10 post-it notes above 6 , and 3 post-it notes above 7 . The plot itself was drawn from 3 inches to 15 inches and labeled Wrist Measurements.

13. Ms. Brown: What if I took these [post-it notes] off; what could I replace them with?

14. Student: $\mathrm{X}$ 's

15. Ms. Brown: What would each X represent?

16. Student: Post-It Notes

17. Ms. Brown: What else?

18. Student: One person

19. Ms. Brown: Yes, one student.

Ms. Brown took off post-it notes and put up X's in spots where post-it notes were.

20. Ms. Brown: As I'm doing this I'm going to make sure this $X$ and this $X$ are at the same level. Why is that important?

21. Student: If not, then you couldn't tell where it is and ...

22. Ms. Brown: So it would be hard to read.

23. Student: If it was up, some people might think the $\mathrm{X}$ was at 2 (2 values up instead of just 1)

24. Ms. Brown: We could have left the post-it notes, but you almost always see X's so it's good for you to see it that way.

The transcript comments 1 to 24 provide an example of what could be expected if the teachers were to receive additional training in the teaching of statistics. This will be discussed further in the implications section of the paper.

Another question from Category $\mathrm{V}$ asked the teachers to provide examples of data sets that would be appropriate for the displays in Figures 5 and 6. These were chosen to determine whether teachers considered the type of variable, categorical or numerical, that might be appropriate for the displays. Values were specifically not included on the horizontal axis as teachers were asked to come up with contexts that would be represented by the displays. The researchers felt that providing values may have restricted the responses to this task and taken away from the purpose of determining whether the teachers could distinguish between continuous and discrete data.

Transcript comments 25 to 32 are a conversation between the researcher and Ms. Clark during this task.

25. Researcher: What type of display is display 1 and what type of Display is Display 2? 
26. Ms. Clark: They both look like bars. I don't believe bars are always supposed to be touching, but that doesn't always seem to be true. So I would call them both bar graphs.

27. Researcher: Can you give me an example of a set of data that could have these types of graphical displays? So start with Display 1. What is an example of a set of data that could be represented with such a data display?

28. Ms. Clark: I guess like maybe a game day. Let's say we were playing kickball and in Game 1 my team scored 3 points, Game 2 we scored 5 points, Game 3 we scored 4 points, Game 4 we scored 6 points, and in Game 5 we scored 2 points.

Or maybe the different times up at bat. So in the first inning my team scored 3 , in the second we scored 5 , and so on.

29. Researcher: What is an example of a set of data that could be represented with Display 2 ?

30. Ms. Clark: Uhm, I could probably use the same kickball example. Maybe on day 2 of game day, the times we were up at bat we scored this number of runs in each inning.

31. Researcher: So is there a difference between the graphical displays? Would you use one to represent a certain type of information?

32. Ms. Clark: I would use both for the same information. Obviously the bars don't reach the same heights on both graphs so they couldn't be the exact same information, but the displays could be used for similar situations. So using my same scenario, the first day when we were first up at bat we got 3 runs and the second day when we were first up at bat we got 2 runs.

I guess if I were going to be more detailed, in graphical Display 1 all the bars are the same color and in graphical Display 2 the bars are different colors.

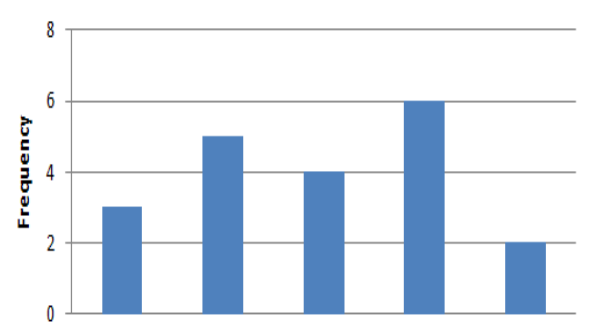

Figure 5. Graphical Display 1

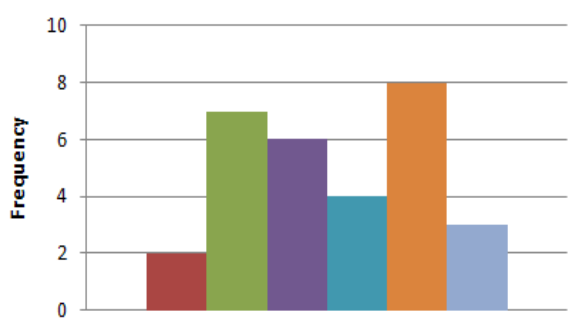

Figure 6. Graphical Display 2

Again the intent of this question was to help inform the researcher of the teachers' understanding between categorical and numerical data. From the example(s) provided by Ms. Clark in transcript comments 25 to 32, it appears that she may not have possessed an understanding that bar graphs are associated with categorical or discrete data whereas histograms are associated with continuous numerical data, or that in histograms the data may be grouped into intervals. She also may not have understood the idea of frequency, associating the vertical axis with the number of runs rather than the number of times a particular value for a variable occurs. By doing so, she treated a situation involving a single variable as one that involved two variables. However, by considering Ms. Alvin's comments in transcript comments 33 to 38, it may be just that the teachers did not recognize the difference between bar graphs and histograms.

These comments stem from a conversation that took place between Ms. Alvin and one of her students during a lesson out of the fourth grade Math Out of the Box materials. This conversation occurred as a result of a direction of the teacher to have students construct bar graphs based on attributes they used to sort a collection of leaves. 
33. Ms. Alvin: If you feel good about your table, I want you to start making your bar graph.

34. Ms. Alvin: For an example of a bar graph look on your desks.

After providing some time for the students to work on this, the teacher created a bar graph on the board based on the table she already had as an example.

35. Student: Ms. Alvin, the bar graph you drew on the board has space between the bars. Should ours have space between the bars?

36. Ms. Alvin: Yes, they should.

37. Student: But the ones on our desks have the bars touching each other.

The teacher walked around the room and noticed that most of the students had constructed bar graphs with the bars touching.

38. Ms. Alvin: You know, I don't think it matters whether the bars are touching or not. There is not a difference between these graphs. You can make your bar graphs either with the bars touching or without the bars touching.

The statements presented in transcript comments 33 to 38 represented the only occasion in the third and fourth grade materials where students were asked to construct bar graphs. The researcher did not attempt to find a third data source for triangulation. As a result, we cannot be certain about indicating that Ms. Clark did not possess the ability of differentiating between the nuances of categorical and numerical data. Again, it is not a critical component for teachers to know whether the bars should or should not touch as it is only a convention. However, it is crucial that teachers understand how to distinguish between categorical and numerical data and to determine whether numerical data had been grouped into intervals. It is also critical that they understand the idea of frequency and are able to identify the variables of interest in a given situation. Future studies should determine whether the issues were in the teachers' recognition of the differences between bar graphs and histograms or if they truly had difficulty distinguishing between categorical and numerical data.

Based upon the recommendations outlined by the GAISE framework, the three teachers involved in this study were not prepared to help students realize the objectives of Levels A and B in regard to data displays. One of the main reasons for this is that the teachers did not have experience with many of the data displays now included in the curriculum. The GAISE framework indicates that, in addition to being able to construct and use various displays, students at Level B should understand the difference between a bar graph and histogram. Part of this recognition involves the realization that certain data displays are more useful in characterizing the data than others depending upon the question of exploration. These results, although not conclusive, reveal that even teachers that are considered exemplary need training in comprehending various data displays. A perfect example of the benefit they can receive from such training is evident in Ms. Brown teaching her students the process for constructing the lineplot.

\section{IMPLICATIONS}

The elementary school teachers involved in this study generally had a low-level comprehension of data displays. The three teachers involved in this study had been recommended by their district supervisor for mathematics and science education and principals as exemplary teachers of mathematics. They were quite effective in developing interest in mathematics and motivating students to succeed, and did an excellent job, as 
evidenced by standardized test scores, in developing number sense and skills. Their gaps in statistical preparation stand in contrast to their confidence and strength in other areas of mathematics. Although the sample of teachers for this study was small, the fact that these teachers were considered exemplary would lead one to wonder what might be expected of teachers who are not considered exemplary.

In order to prepare teachers for teaching statistics at the level proposed by the authors of the GAISE, they must not only be exposed to experiences with statistical content during their preservice teacher training or through sustained professional development, which may not be occurring, but they must be given multiple opportunities to master the underlying concepts.

\subsection{IMPLICATIONS FOR TEACHER TRAINING}

As suggested by Friel et al. (2001),

To provide effective instruction, teachers need to increase their knowledge of graphs and how to teach graphs. Because of the recent emphasis on statistics and data analysis, graphs have only recently become an important part of the elementary and middle school mathematics curriculum. Consequently, teachers may not have had adequate opportunities to learn about graphs. (p. 153)

The three teachers involved in this study did not possess a level of comprehension of data displays as outlined at Levels A and B of the GAISE framework. If students are to be expected to develop sophisticated understanding of data displays as suggested by standards writers in many countries, it is important that teachers thoroughly understand the concepts and procedures at least one level beyond the level they will teach. Because these expectations are relatively new, most preservice teachers are likely not to have had sufficient experiences during their schooling to develop such an understanding. As a result, teacher preparation programs might place more emphasis on understanding data displays as well as other areas of statistics.

The discipline of statistics goes beyond the focus of this study. Statistics also involves the formulation of questions, the design of studies to answer those questions, and the use of statistical tools to make inferences about populations and processes based on samples. At an international level, these ideas should become a focus during teacher preparation programs for elementary teachers in order to help them develop a sophisticated understanding of the content.

As discussed previously, students must progress through the experiences suitable for Level A before moving onto Level $\mathrm{B}$, and thus must progress through appropriate experiences at Level B before moving onto Level C. If students are expected to make such a progression, then so should teachers. Without this progression, teachers may have difficulty developing the sophistication expected in order to be prepared to teach students at such an advanced level. Addressing teachers' knowledge during preparation programs might help new teachers; however this implication can only have an impact on teachers that are not yet in the field. On-going professional development opportunities must also provide in-service teachers with the necessary experiences so that they too will be prepared for the classroom.

\subsection{IMPLICATIONS FOR PROFESSIONAL DEVELOPMENT}

These three inservice teachers could benefit from professional development training that focuses on the development of statistical content knowledge. This is clearly exhibited by all three teachers' ability to successfully introduce the process of constructing a 
lineplot when they had first not understood the display. By the end of the study, all three teachers had acknowledged an awareness of their lack of comprehension of data displays and a desire to receive professional development focused on this particular content strand. Although the teachers' interaction with the curriculum materials and the assessments implemented by the researcher did not sufficiently influence the teachers' comprehension of data displays, it did cause them to reconsider the suitability of their own content knowledge. In other words, this interaction made them aware of problems in their knowledge.

Once teachers recognize new viewpoints or what may be lacking in their own understanding, problematization occurs. Problematizing teachers' knowledge is essential for professional development to be successful in changing teachers' preparedness for teaching statistics (Cobb \& Bauersfeld, 1995). Teachers who realize they have a lack of understanding in a particular area are more likely to benefit from professional development focused on content. The three teachers involved in this study provide an example that illustrates the importance of such a realization. Similar to Begg and Edwards' (1999) findings, at the beginning of the study the teachers preferred activities and more than likely would have avoided or half-heartedly participated in professional development focused on content. However, toward the end of the study, the teachers indicated they preferred professional development focused on content. With the problematization they experienced, the teachers, at the least, became more willing to learn the content introduced during professional development. This study emphasizes the importance of providing teachers with professional development to address the increased international expectations to teach statistics at a deeper level. In many countries teachers receive only a one-year training period after their initial degree before entering the classroom. For them, professional development opportunities will be the only avenue to help them develop deeper levels of statistical understanding.

\section{IMPLICATIONS FOR CURRICULAR DEVELOPMENT}

Traditional textbooks tend to ask questions which focus on reading information from data displays (Category I). These types of questions are not sufficient to assess the level of understanding described by the authors of the GAISE framework. However, textbooks are not the only medium in which low-level questions are posed to students.

Konold and Khalil (2003) examined the levels of questions posed on high-stakes tests in the area of data analysis. The results of their work shed light on why many students associate statistics with "doing something with numbers" (Category II). They claim that test developers for these examinations interpret data analysis and statistics as taking information from a graph. Many questions, in fact, involve examining only a graph and finding a particular point (Category I). Konold and Khalil conclude that "current highstakes assessments are virtually ignoring all but the most rudimentary skills in data analysis" (p. 6).

Asking questions which force students to look beyond the data displays helps them develop conceptual knowledge of essential topics in statistics. Furthermore, if the students are to think beyond the data displays, then the teachers also have to think beyond the data displays.

\section{CONCLUSIONS}

At the beginning of this paper, we listed several standards that NCTM suggests that all students in the United States should master during Grades 3-5 (ages 9-11). Sadly, we discovered that the teachers in this study had not mastered these ideas themselves. This, 
however, is in no way an indictment of the teachers, but rather is a call to those of us who work with the development of both preservice and inservice teachers. We cannot expect people to have a mastery of ideas that they have not been taught. The elementary school teachers involved in this study were considered exemplary teachers of mathematics by their district supervisor and principals. If teachers who are considered exemplary do not possess the necessary comprehension to help students realize the objectives of increased international expectations, then we can infer that teachers who are not considered exemplary also do not possess such knowledge. In order to prepare elementary school teachers to teach statistics as described in the GAISE framework, teachers should progress through the levels of statistical understanding themselves. Teachers who are unprepared to teach statistics face an unfair situation where they have not mastered the material they are now called upon to teach. The expectations for students cannot be increased without addressing teachers' preparation to meet those expectations.

\section{REFERENCES}

Batanero, C., Godino, J., \& Navas, F. (1997). Concepciones de maestros de primaria en formción sobre promedios [Primary school teachers' conceptions on averages]. In H. Salmerón (Ed.), Actas de las VII Jornadas LOGSE: Evaluación Educativa (pp. 310340). Granada, Spain: University of Granada.

Begg, A., \& Edwards, R. (1999, December). Teachers' ideas about teaching statistics. Paper presented at the Joint Conference of the AARE and NZARE, Melbourne.

Bertin, J. (1983). Semiology of graphics ( $2^{\text {nd }}$ ed., W. J. Berg, Trans.). Madison: University of Wisconsin Press.

Cai, J., \& Gorowara, C. C. (2002). Teachers' conceptions and constructions of pedagogical representations in teaching arithmetic average. In B. Phillips (Ed.), Proceedings of the Sixth International Conference on Teaching Statistics: Developing a statistically literate society, Cape Town, South Africa. [CD-ROM]. Voorburg, The Netherlands: International Statistical Institute.

[Online: http://www.stat.auckland.ac.nz/ iase/publications/1/2c1_cai.pdf]

Callingham, R. (1997). Teachers' multimodal functioning in relation to the concept of average. Mathematics Education Research Journal, 9(2), 205-224.

Carswell, C. M. (1992). Choosing specifiers: An evaluation of the basic tasks model of graphical perception. Human Factors, 34(5), 535-554.

Cobb, P., \& Bauersfeld, H. (Eds.). (1995). The emergence of mathematical meaning: Interacting in classroom cultures (studies in mathematical thinking and learning). Hillsdale, NJ: Lawrence Erlbaum.

Curcio, F. R. (1987). Comprehension of mathematical relationships expressed in graphs. Journal for Research in Mathematics Education, 18(5), 382-393.

delMas, R. C. (2004). A comparison of mathematical and statistical reasoning. In D. BenZvi \& J. Garfield (Eds.), The challenges of developing statistical literacy, reasoning, and thinking (pp. 79 - 96). Dordrecht, The Netherlands: Kluwer.

delMas, R., Garfield, J., \& Ooms, A. (2005). Using assessment ítems to study students' difficulty reading and interpreting graphical representations of distributions. In K. Makar (Ed.), Proceedings of the 4th International Research Forum on Statistical Reasoning, Thinking, and Literacy. University of Auckland.

[Online: https://app.gen.umn.edu/artist/articles/SRTL4_ARTIST.pdf]

Espinel, M. C., Bruno, A., \& Plasencia, I. (2008). Statistical graphs in the training of teachers. In C. Batanero, G. Burrill, C. Reading, \& A. Rossman (Eds.), Joint ICMI/IASE Study Statistics in School Mathematics. Challenges for Teaching and 
Teacher Education. Proceedings of the ICMI Study 18 Conference and IASE 2008 Round Table Conference. Monterrey: ICMI and IASE.

[Online: http://www.stat.auckland.ac.nz/ iase/publications/rt08/T2P11_Espinel.pdf]

Franklin, C., Kader, G., Mewborn, D., Moreno, J., Peck, R., Perry, M. et al. (2007). Guidelines for assessment and instruction in statistics education (GAISE) report. Alexandria, VA: American Statistical Association.

Friel, S. N., Curcio, F. R., \& Bright, G. W. (2001). Making sense of graphs: Critical factors influencing comprehension and instructional implications. Journal for Research in Mathematics Education, 32, 124-158.

Gfeller, M. K., Niess, M. L., \& Lederman, N. G. (1999). Preservice teachers' use of multiple representations in solving arithmetic mean problems. School Science and Mathematics, 99(5), 250-257.

Greer, B., \& Ritson, R. (1994). Readiness of teachers in Northern Ireland to teach Data Handling. Proceedings of the Fourth International Conference on Teaching Statistics, Vol. 1, pp. 49-56, Marrakech, Morocco.

Groth, R. E. (2007). Toward a conceptualization of statistical knowledge for teaching. Journal for Research in Mathematics Education, 38(5), 427-437.

Groth, R. E., \& Bergner, J. A. (2006). Preservice elementary teachers' conceptual and procedural knowledge of mean, median, and mode. Mathematical Thinking and Learning, 8(1), 37-63.

Hill, H. C., Ball, D. L., \& Schilling, S. G. (2008). Unpacking pedagogical content knowledge: Conceptualizing and measuring teachers' topic-specific knowledge of students. Journal for Research in Mathematics Education, 39(4), 372-400.

Jacobbe, T. (2008). Elementary school teachers' understanding of the mean and median. In C. Batanero, G. Burrill, C. Reading, \& A. Rossman (Eds.), Joint ICMI/IASE Study Statistics in School Mathematics. Challenges for Teaching and Teacher Education. Proceedings of the ICMI Study 18 Conference and IASE 2008 Round Table Conference. Monterrey: ICMI and IASE.

[http://www.stat.auckland.ac.nz/ iase/publications/rt08/T2P13_Jacobbe.pdf]

Jacobbe, T. (2007). Elementary school teachers' understanding of essential topics in statistics and the influence of assessment instruments and a reform curriculum upon their understanding. Unpublished doctoral dissertation, University of Kentucky. [Online: www.stat.auckland.ac.nz/ iase/publications/dissertations/dissertations.php]

Konold, C., \& Khalil, K. (2003, April). If U can graff these numbers-2,15,6-your stat literate. Paper presented at the annual meeting of the American Educational Research Association, Chicago, IL.

Leavy, A., \& O'Loughlin, N. (2006). Preservice teachers' understanding of the mean: Moving beyond the arithmetic average. Journal of Mathematics Teacher Education, 9(1), 53-90.

McKnight, C. C. (1990). Critical evaluation of quantitative arguments. In G. Kulm (Ed.), Assessing higher order thinking in mathematics (pp. 169-185). Washington, D.C.: American Association for the Advancement of Science.

Miles, M. B., \& Huberman, A. M. (1994). Qualitative data analysis. Thousand Oaks, CA: Sage.

Moss, D., Diaz, D., Lashley, E. Moss, W., \& Sanders, S. (2005). Developing algebraic thinking: Plotting and growing, Teacher's manual, Third Grade. Burlington, NC: Carolina Biological Supply.

National Council of Teachers of Mathematics. (1989). Curriculum and evaluation standards for school mathematics. Reston, VA: Author. 
National Council of Teachers of Mathematics. (2000). Principles and standards for school mathematics. Reston, VA: Author.

Russell, S. J., \& Mokros, J. R. (1990). What's typical? Children's ideas about average. In D. Vere-Jones (Eds.), Proceedings of the Third International Conference on Teaching Statistics (pp. 307-313). Voorburg, The Netherlands: International Statistical Institute.

Saderholm, J., Ronau, R., Todd Brown, E., \& Collins, G. (2010). Validation of the Diagnostic Teacher Assessment of Mathematics and Science (DTAMS) Instrument. School Science and Mathematics, 110(4), 180-192.

Scheaffer, R. (1986). The quantitative literacy project. Teaching Statistics, 8(2), 34-38.

Schön, D. A. (1983). The reflective practitioner: How professionals think in action. New York: Basic Books.

Shaughnessy, J. M. (2007). Research on statistics learning and reasoning. In F. K. Lester (Ed.), Second handbook of research on mathematics teaching and learning (pp. 9571009). Reston, VA: National Council of Teachers of Mathematics.

Shaughnessy, J. M., Garfield, J., \& Greer, B. (1996). Data handling. In A. J. Bishop, K. Clements, C. Keitel, J. Kilpatrick, \& C. Laborde (Eds.), International Handbook of Mathematics Education (pp. 205-237). Dordrecht, The Netherlands: Kluwer.

Wainer, H. (1992). Understanding graphs and tables. Educational Researcher, 21(1), 1423.

TIMOTHY JACOBBE

School of Teaching and Learning

PO Box 117048

2403 Norman Hall

University of Florida

Gainesville, FL 32611 